\title{
Effect of Graphene Loading on Mechanical and Morphological Properties of Recycled Polypropylene/Polyaniline Nanocomposites
}

\author{
M. R. Husin ${ }^{\mathrm{a}}$, AgusArsad ${ }^{\mathrm{b}}$, Othman Al-Othman $^{\mathrm{c}}$ \\ ${ }^{\mathrm{a}, \mathrm{b}}$ Enhanced Polymer Research Group, Department of Polymer Engineering, Faculty of Chemical Engineering, Universiti Teknologi \\ Malaysia, Johor, 81310 Skudai, Malaysia \\ ${ }^{\mathrm{C} C h e m i c a l}$ Eng. Department, College of Engineering, King Saud University, Riyadh 1142a, Saudi
}

\begin{abstract}
The investigation of the graphene (GN) performance in improving mechanical properties of recycled polypropylene with crosslinkedpolyaniline (rPP-g-PANI) was prepared via ultrasound extrusion. The concentration of GN in the research was varied from 0.5 to $3 \mathrm{phr}$, while polyaniline (PANI) and dycumil peroxide(DCP) were fixed at 4 wt. $\%$ and $1 \mathrm{phr}$ loading, respectively. The morphological structure of the nanocomposites was investigated using fill emission scanning electron microscopy (FESEM) and confirmed a good dispersion of PANI and GN on rPP matrix. The increasing loading of GN has promoted a slight improvement in tensile modulus and tensile strength at 1.5 and 2 phr of GN loadings, respectively. However elongation at break showed a decrease at all PANI loadings due to lack of interfacial addition between PANI/GN particles and the rPP matrix.
\end{abstract}

\section{Introduction}

Polypropylene (PP) constitutes one of the major plastics waste in the landfill, which raise environmental concern [1]. Therefore, the need to recycle large amount of used PP is becoming one of the viable and promising solutions. The use to recycled PP (rPP) as a matrix material in various composites has enable wider applications in high value applications. An aggressive research being done on the use of cleaner technologysuch as ultrasonic processing in the recycling technology contributes to reducing the impact of industrialization upon the environment [2]. However rPP alone is lack of sufficient properties, which hinder the use in some engineering applications. To overcome this problem, conductive polymer was employed in the production of recycled polymer matrix.

Polyaniline (PANI) is a unique conducting synthetic polymer with good chemical, electrical, and optical properties. The most important properties of PANI include their controllable electrical conductivity, lower density than metals, good environmental stability, and ease of preparation from common chemicals [3]. However the main problem of PANI is associated with the hardness and brittleness of free standing PANI that make them difficult for processing. To overcome this problem, rPPwas processed together with PANI, which exhibit balancedproperties of electrical conductivity, mechanical properties, and processing characteristics.Owing to the chemical structure, Dicumyl peroxide (DCP) serve in this mixture as acrosslinking agent and acted as compatibilizer of rPP-
PANI and to promote coupling through crosslinking between PANI and rPP resin. The mixturewas shown to havea good processing behaviour and can be processed thermally below temperatures [4].A composite consisting of conductive fillers and an insulating polymer becomes electrically conductive as the filler content exceeds a certain critical value. Recently, twodimensional structures based on $\mathrm{GN}$ has received significant attention owing to its astonishing electronic, thermal and mechanical properties [5]. Till date several researches have been carried out based on polymer composites using $\mathrm{GN}$ as nanofiller [6].With the resident time of the ultrasonic treatment of a few seconds, the use of high power ultrasound in extrusion process might enhance dispersion of nanosize filler in polymer matrix. In particular, it was found that the ultrasound-assisted extrusion has resulted in better silica filler dispersion in rubber [7] and nanoclay intercalation and exfoliation in PP [8] and Polyethylene (PE) matrices [9].In this paper, recycled polypropylene (rPP) was used as matrix material, PANI and grapheneas a conductive materials and DCP as crosslinking agent to produce rPP-PANI compositessuitable for development of new conductive material. Mechanical and morphological of the obtained blends were studied.

\section{Experimental}

\subsection{Materials.}

Recycled polypropylene (rPP) resin was purchased from Titan Petrochemical, Malaysia.Dicumyl peroxide 99\% was purchased from Acros Organics, New Jersey, USA.

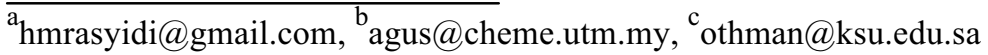


Analine: Aniline (99\%) and ammonium persulfate (APS) were purchased from Sigma-Aldrich and hydrochloric acid $37 \%$ (HCL) were obtained from Tosla. Graphene (GN) nanoplatelets, GNP-M-5 grade (99.5\% carbon) of average diameter $5 \mathrm{~mm}$ and average thickness of less than $10 \mathrm{~nm}$ were purchased as dry powder from XG Sciences (East Lansing, MI). Nanosized PANI was synthesized using emulsion polymerization method as describe in our previous work [10] in the presence of aluminum per sulfate and hydrochloric acid at $0^{\circ} \mathrm{C}$ using ultrasonic reactor.

\subsection{Preparation of rPP-PANI/ GNnanocomposites.}

rPP, PANI, DCP andGN at various ratios were melt blended using a ultrasound single screw extruder at processing temperature $150-170^{\circ} \mathrm{C}$ and the screw speed was $50 \mathrm{rpm}$. The $\mathrm{rPP}$ containing 0.5-3 phrGN, PANI and DCP were kept constant at 4 wt. $\%$ and 1 phr, respectively. The materials were extruded through water bath, pelletized and then dried at $80 \mathrm{C}$ for $24 \mathrm{~h}$ before injection in an injection molding (HAITIAN HTF 58X). The temperatures from the hopper to the nozzle were 170 to $200^{\circ} \mathrm{C}$. Standard test samples (ASTM standards) were produced for mechanical and morphological tests. All tests were conducted more than $24 \mathrm{~h}$ after injection.

\section{Composites characterization}

The effect of different loading of PANI in rPP matrix to the mechanical properties of the rPP-PANI blend were evaluated by tensile and impact strength testing according to ASTM D412 and ASTM D256 respectively on the least 7 specimens for each formulation. Tensile test was performed using Lloyd testing machine with testing speed $50 \mathrm{~mm} / \mathrm{min}$. All tests were carried out under ambient conditions.Dispersion of the GN and nanosized PANI was observed using fill emission scanning electron microscopy (FESEM) of rPP-PANI/GN nanocomposites fractured samples was performed using a NOVA NANOSEM 450, at an accelerating voltage of $5 \mathrm{kV}$. Prior to observation samples were platinum sputtered. A micrograph was analyzed at $10 \mathrm{Kx}$ magnification.

\section{Result and discussion}

\subsection{Mechanical analysis}

Fig. 1.(a - c) shows the effect of GNloading on tensile strength, elastic modulus and elongation at break of the rPP-PANI blends and rPP-PANI/GN nanocomposites. It can be observed in Fig. 1.a) that the tensile strength sharplydecreased at $0.5 \mathrm{phr}$, followed by increasing trend from $1.0 \mathrm{phr}$ until reaching the optimum tensile strength at $1.5 \mathrm{phr}$. However, the increase of GN loading above $1.5 \mathrm{phr}$ show decreasing trend of tensile strength. The increment in tensile strength at $1.5 \mathrm{phr}$ GN was believed to be attributed by uniform distribution of PANI and GN on the rPP matrix because the addition of DCP and the application of ultrasound extrusion.From Fig. 1.b), the elastic modulus showed drasticallydecreased at $1.0 \mathrm{phr}$,followed by increasing trend from $1.5 \mathrm{phr}$ until reaching the optimum elastic modulus at $2.0 \mathrm{phr}$. However, the elastic modulus decreased after subsequently loading of GN. Similar observation by Jiang and co-workers also proved the ability of ultrasound extrusion to enhanced mechanical properties [11]. They also discovered that the crystal size of polymer matrix was decreased due to ultrasonic oscillations that lead to decrease dispersion phase PANI and its distribution in polymer matrix. As a conclusion, the DCP successfully incorporated into the system at 1.5 phrof GN loadings and forming a crosslinking effect to the rPP-PANI/GN nanocomposites. The decrease in tensile strength and elastic modulus is due to agglomeration of the $\mathrm{GN}$ at higher concentration leading to poor adhesion between the filler and matrix and the increase in filler-filler interaction due the restacking of the GN. The elongation at break shown in Fig. 1.c) was found to decrease by $52 \%$ with addition of $0.5 \mathrm{phr}$, following by subsequently increasing at 1.0 phr.All results in Fig. 1 $(\mathrm{a}-\mathrm{c})$ have shown that the tensile strength, elastic modulus and elongation at break dropped drastically at range point of 0.5 to $1.0 \mathrm{phr}$ of GN loading. It is assumed that the addition of low loading GN occurs due to the Van der Waals interaction between the GN and rPP matrix is lower. During the tensile test occurred slippage of piled graphene sheets will have less effective enhancement on the strength [12].

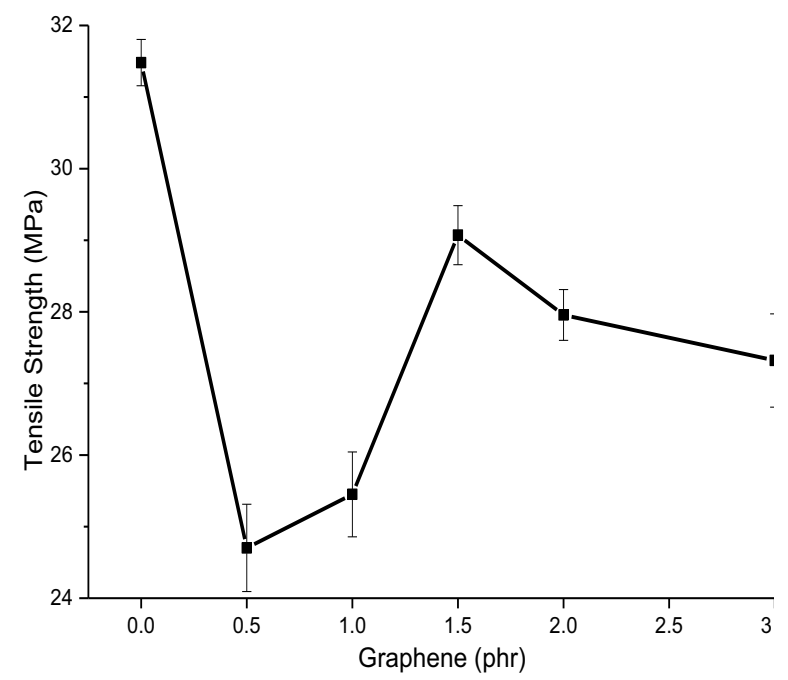



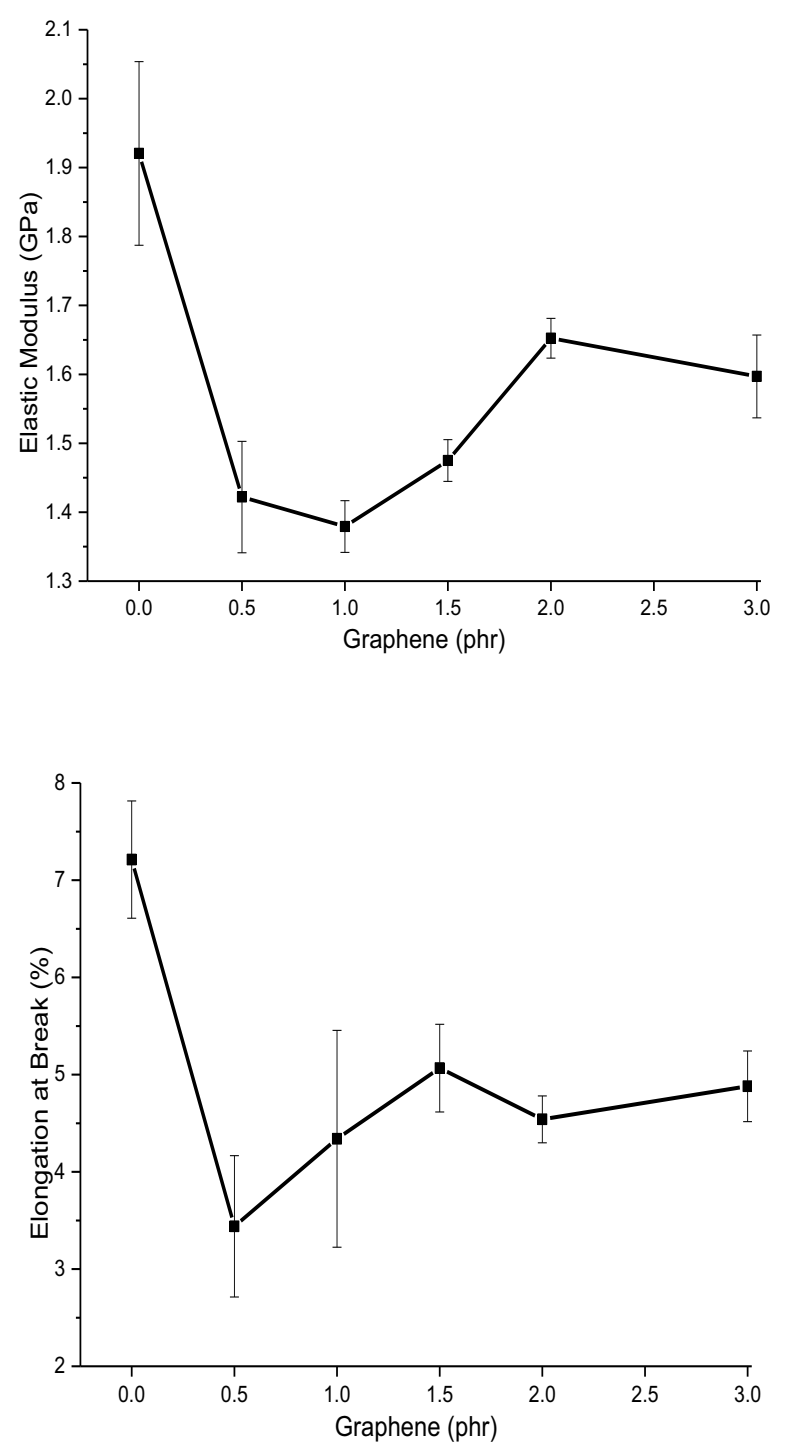

Figure 1.Effect of GN loadings on the (a) tensile strength, (b) elastic modulus and (c) elongation at break of rPP/PANI/GN nanocomposites

\subsection{Morphological analysis.}

Fig. 2 shows the FESEM micrographs taken at the tensile fracture surface after deformation measurements for blend rPP-PANI (a) and its nanocomposite (b), and it can be seen that the platelets were intact and dispersed into the rPP matrix, with no sign agglomeration. The Fig. 2.(a) show the presence of the PANI nanoparticles and the distribution PANI nanoparticles in rPP matrix. At percentage concentration (4 wt.\%), the uniform dispersion of PANI particles was caused by the use of DCP crosslinking agent and ultrasonic extrusion [13]. The PANI particles were found embedded in rPP matrix with possible through certain degree of chemical bonding between two phases (rPP and PANI) and may indicate that the DCP contents enough to chemical bonding. The Fig. 2.(b) show the GN plate can be seen projecting out of the fracture surfaces. Blend rPP-PANI exhibits a smooth surface, while nanocomposites show layered structures because GN is well covered by the polymeric matrix. The GNwas distributed uniform in the rPP matrix. The uniform dispersion of GN in the matrix at this filler concentration is through to be responsible for the enhancement of tensile properties. Jiang and Drza [14] presented similar morphology on the investigation of GN reinforced high-density polyethylene by melt mixing.

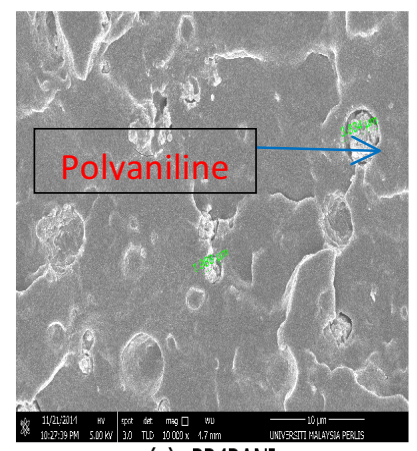

(a) rPP4PANI

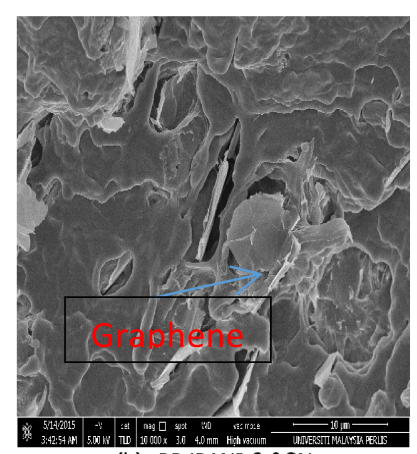

(b) rPP4PANI-2.0GN
Figure 2. FESEM images of the tensile fractureof neatrPP and rPP-PANI/GN nanocomposites

\section{Conclusions}

GN reinforced rPP-PANI nanocomposites were successfully prepared by ultrasonic extrusion. Result of tensile test showed that the improvement in both tensile strength and elastic modulus was observed in rPP4PANI/GN nanocomposites at 1.5 and 2.0 phrof GN loading. The improvements obtained for the mechanical properties are attributed to stiffness of the platelets, effective stress transfer between rPP matrix, PANI and $\mathrm{GN}$ and uniform dispersion of GNs in the matrix. In contrast, the elongation at break of rPP-PANI/GN nanocomposites drastically decreased with increasing GN loading at 0.5 phr. FESEM analysis showed GN and PANI nanoparticles were dispersed uniformly in rPP matrix. It can be concluded that the rPP-PANI blends with homogeneous distribution of PANI nanoparticles in rPP matrix was successfully developed by the use of DCP crosslinking agent and ultrasonic extrusion.

\section{Acknowledgements}

The authors would like to thank the Ministry of Education (MOE), Malaysia, for the FRGS Grant (Vot no.: 4F288), Universiti Teknologi Malaysia, for the facilities provided.

\section{References}

1. D.S. Achilias, C. Roupakias, P. Megalokonomos, A.A. Lappas, E.V. Antonakou. Chemical recycling of plastic wastes made from polyethylene (LDPE and HDPE) and polypropylene (PP). Journal of Hazardous Materials.149(2007)536-542.

2. F.M.B. Coutinho and T.H.S Costa. Performance of polypropylene-wood fiber composites. Polymer Testing.18(1999)581-587.

3. J.E. Osterholm, Y. Cao, F. Klavetter, P. Smith. Emulsion polymerization of aniline. Synthetic Metals. 552-3(1993)1034-1039. 
4. R. Fryczkowski, W. Biniaś, J. Farana, B. Fryczkowska, A. Włochowicz. Spectroscopic and morphological examination of polypropylene fibres modified with polyaniline. Synthetic Metals. 145:2-3(2004)195-202.

5. C. Berger, Z. Song, T. Li, X.B. Li, A.Y. Ogbazghi and R. Feng et al., Ultrathin epitaxial graphite: 2D electron gas properties and a route toward graphene based nanoelectronics. J PhysChemBvol. 108:52(2004)19912-19916

6. A.V. Raghu, Y. R. Lee, H. M. Jeong and C. M. Shin, Preparation and physical properties of waterborne polyurethane/functionalized graphene nanocomposites. MacromolChem Phys. 209:24(2008)2487-2493.

7. A. I. Isayev, C. K. Hong, and K. J. Kim. Continuous Mixing and Compounding of Polymer/Filler and Polymer/Polymer Mixtures with the Aid of Ultrasound. Rubber Chemistry and Technology. 76:4(2003)923-947.

8. L. Sergey and A. I. Isayev. Continuous process for melt intercalation of PP-clay nanocomposites with aid of power ultrasound Journal of Vinyl and Additive Technology.12:2(2006)78-82.

9. S. K. Swain, and A. I. Isayev. Effect of ultrasound on HDPE/clay nanocomposites: Rheology, structure and properties. Polymer. 48:1(2007)281289.

10. M. R. Husin, A. Arsad and O. Y. Alothman. Synthesis of Nano-Polyaniline Using Different Ultrasonic Wave. Applied Mechanic and Materials. 695(2014)207-210.

11. L. Jiang, Z. Lijuan, G. Shaoyun. Ultrasonic Preparation of Polymer/Layered Silicate Nanocomposites during Extrusion. Polymer Bulletin. 55(2005)217-223.

12. X. Zhao, Q. Zhang, D. Chen, P. Lu. Enhanced Mechanical Properties of Graphene-Based Poly(vinyl alcohol). Composites. Macromolecules 43(2010)2357-2363.

13. M.R. Husin, A. Arsad, M.S.Z. Mat Desa, M.F. Abdul Rahman.Influence of Nano-Polyaniline Contents on Mechanical Properties of Crosslink Recycled Polypropylene Polyaniline.Advanced Materials Research. 1125(2015)13-17.

14. X. Jiang and L. T. Drza. Multifunctional High Density Polyethylene Nanocomposites Produced by Incorporation of Exfoliated Graphite Nanoplatelets 1: Morphology and Mechanical Properties. Polymer Composites. 31:6(2010)1091-1098. 